Article

\title{
Cooling Energy Implications of Occupant Factor in Buildings under Climate Change
}

\author{
Ji Hyun Lim and Geun Young Yun * \\ Department of Architectural Engineering, Kyung Hee University, Gyeonggi-do 17104, Korea; wlgus@khu.ac.kr \\ * Correspondence: gyyun@khu.ac.kr; Tel.: +82-31-201-3859
}

Received: 24 October 2017; Accepted: 6 November 2017; Published: 7 November 2017

\begin{abstract}
Occupant factor is a critical element in the overall energy consumption of buildings. This study aims to reveal how occupant factors influence the energy consumption of example buildings in Seoul, Tokyo, and Hong Kong under climate change projections, and to prioritize factors with energy saving potential for buildings in consideration of future climate change. The study finds that the cooling degree-hours base of $23.3^{\circ} \mathrm{C}$ in the three cities sharply increases with future climate change by analyzing future hourly weather data produced herein. Simulations are made with EnergyPlus Runtime Language (Erl) for modeling occupant behavior. The simulation results reveal that a dynamic thermostat control based on an adaptive comfort model is an effective method to reduce cooling energy consumption under future climate change, reducing cooling energy consumption by up to $18 \%$ in some instances. In particular, we reveal that a combined application of the adaptive comfort control, nighttime ventilation, and the use of occupancy-based lighting and equipment result in reducing cooling energy consumption by $28 \%$. The outcomes of this study are potentially useful in providing cost-effective solutions to adapt buildings for future climate change with simple modifications to occupant behavior. Also, the roles of renewable energy are briefly discussed.
\end{abstract}

Keywords: occupant factor; adaptive comfort; climate change; nighttime ventilation; future weather data; energy savings

\section{Introduction}

Climate change receives a lot of attention because of its potentially devastating consequences for both the environment and humans. Climate-related extremes, including heat waves, droughts, cyclones, and floods have caused severe damage in both developing and developed countries [1]. Globally, the health of 9 billion people is foreseeably threatened by the direct effects of climate change, and the World Health Organization (WHO) estimates that climate change will cause 250,000 additional deaths per year between 2030 and 2050 [2]. On one hand, the building sector is one of the largest contributors to global greenhouse gas (GHG) emissions, which are the most significant driver of climate change. Greenhouse gas emissions from buildings have sharply increased since 1970, accounting for $25 \%$ of global GHG emissions in 2010 [3]. Most GHG emissions from buildings are related to energy use for heating, cooling, ventilation, and lighting. In particular, GHG emissions from energy use in buildings have shown active growth since 1970 and are expected to double by the middle of this century due to increases in wealth, lifestyle changes, and urbanization.

On the other hand, the building sector has the largest cost-effective potential for reducing energy use in comparison to other sectors [4]. New and improved technology for energy efficiency provides cost-effective solutions that are projected to achieve 2-to-10-fold reductions in the energy consumption of individual buildings. Key technologies include mechanisms for daylighting and electric lighting control [5], high performance building envelopes [6], advanced heating, ventilating, 
and air-conditioning (HVAC) systems [7,8], and intelligent energy management systems [9]. Regardless, the energy saving potential of these advanced technologies has not always materialized in practice due to an insufficient understanding of the significant role of occupant behavior in the energy consumption of buildings. Field measurements indicate that the actual energy consumption of a building is considerably greater (often two times higher) than the predicted energy use at the design stage due to inaccurate assumptions about the occupant factor [10,11].

The occupant factor is a key element in determining the energy consumption of any building. Existing studies show that there are two-to-five-fold variations in energy use for similar buildings in the same climate and with the same functions $[10,12]$. It is also estimated that the design and operation of a building that carefully accounts for occupant behavior can reduce the energy consumption of the building by up to $50 \%$ [13]. Therefore, in order to achieve energy savings in buildings, it is critical to bridge gaps in our knowledge regarding how occupants use buildings.

Existing studies confirm that the overall energy consumption of a building is closely related to occupancy patterns $[14,15]$. Some studies on occupants are related to the use of passive and active environmental control systems in buildings. For example, the use of windows by building occupants has been shown to be closely related to prevailing indoor and outdoor conditions [16,17]. Field studies on the use of air-conditioning systems by building occupants are relatively rare, but the existing research reveals that occupant control of air-conditioning systems is a key determinant in changes in building energy consumption $[18,19]$. Thus, it is evident that occupant behavior should be considered in any analysis of the effects of climate change on energy use in buildings.

Based on previous studies that investigate occupant factor and climate change implications in buildings, this study aims to reveal how factors related to occupant behavior influence the energy consumption of buildings in Seoul, Tokyo, and Hong Kong according to climate change forecasts. Additionally, we aim to prioritize occupant factors that have energy saving potential in buildings in consideration of future climate change. Following an explanation of our method to generate future weather data for energy simulations, this paper describes general assumptions about occupant factor in terms of occupancy patterns, internal gains, lighting and HVAC system use, and thermostat controls. In addition, we describe a simulation method to evaluate the effects of occupant factor and climate change on building energy consumption. Finally, this paper presents simulation results and discusses the outcomes of the study.

\section{Methods}

\subsection{Future Weather Data Generation}

This study utilizes a case study building located in Seoul, Korea, which falls into climate zones $4 \mathrm{~A}$ and $4 \mathrm{~B}$, as specified by ASHRAE Standard 90.1-2013 [20]. The heating and cooling degree days (which are measurements designed to reflect the demand for energy needed to heat and cool a building) for buildings in Seoul are 2782 and 2198, respectively. In order to generate Seoul weather data for purposes of whole building energy simulation programs that account for future climate change, we used the climate change world weather file generator, CCWorldWeatherGen [21]. The CCWorldWeatherGen software is based on a morphing procedure [22] that combines present-day observed weather data with future climate change forecasts by global circulation models (GCM). The morphing method applies locally measured weather data as the baseline climate, while capturing weather conditions of future climate scenarios. Thus, the method is meteorologically consistent. As a GCM, the CCWorldWeatherGen uses a climate prediction model from the UK Met Office Hadley Centre known as the Coupled Model version 3 (HadCM3) to provide mean-monthly projections for three time slices including 2011-2040 (2020s), 2041-2070 (2050s), and 2071-2100 (2080s). These projections are downscaled to fine spatial and temporal resolutions for building energy simulations. The CCWorldWeatherGen is based on an emissions scenario generated by the Intergovernmental Panel on Climate Change (IPCC) known as the A2 emissions scenario, which 
represents a "business as usual" case for global development. The reliability of the morphing method has been verified by the work of Jentsch et al. [23].

\subsection{Case Study Model}

A large office model, which is one type of commercial reference building prepared by the US Department of Energy (US DOE) [24], was chosen as a case study for our purposes of analysis. Based on the Commercial Buildings Energy Consumption Survey (CBECS) conducted by the US Energy Information Administration (EIA), models for commercial reference buildings are developed by the US DOE, National Renewable Energy Laboratory (NREL), Pacific Northwest National Laboratory (PNNL), and the Lawrence Berkeley National Laboratory (LBNL). Our case study is based on the large office model because the model is constructed for energy-related research, and realistically represents building characteristics and practices.

The large office model is a 12-floor building with a total floor area of $46,320 \mathrm{~m}^{2}$. The floor to ceiling height is $2.74 \mathrm{~m}$, and the aspect ratio of the building is 1.5 with an azimuth of $0^{\circ}$. The window to wall ratio for each orientation is 0.40 . The fabric of the large office model has been constructed to comply with ASHRAE Standard 90.1-2013. The U-values of the external walls and windows of the medium office model are $0.591 \mathrm{~W} /\left(\mathrm{m}^{2} \mathrm{~K}\right)$ and $2.371 \mathrm{~W} /\left(\mathrm{m}^{2} \mathrm{~K}\right)$, respectively.

The large office model in this study is equipped with four variable refrigerant flow (VRF) systems and six energy recovery ventilators (ERV). This is because VRF systems are widely used in the Asia-Pacific region - which includes China, Japan, and South Korea-and the VRF systems market had an expected annual increase of $11 \%$. The model has two internal core zones and six parameter zones. In line with our methods, the internal core zones were served by two $16 \mathrm{HP}$ outdoor units, while two $14 \mathrm{HP}$ outdoor units provided heating and cooling to the parameter zones. The cooling and heating capacities of the outdoor unit for each thermal zone were enough to cover the peak cooling and cooling loads of the serving zone, including a safety factor of $10 \%$.

\subsection{Scenarios}

We constructed five scenarios to investigate the implications of adaptive comfort control. The first factor under consideration is internal heat gains from occupants, lighting, and equipment, because it greatly influences the cooling and heating loads of a building. Scenario 1 (the base case scenario) was based on the specifications of the US DOE large office model. The occupancy was set at $18.6 \mathrm{~m}^{2}$ per person, and the lighting and equipment heat gains were both set at $10.76 \mathrm{~W} / \mathrm{m}^{2}$. On a daily basis, occupancy began at $7 \mathrm{a}$.m. and reached a highest value of $95 \%$ at 9 a.m. The number of occupants began to reduce gradually at 6 p.m., and the building became fully vacant at 1 a.m. In the same timeframe, the proportion of lighting turned on was between $5 \%$ and $90 \%$. Ninety percent of all lighting was assumed to be on during normal office hours (from 9 a.m. to 6 p.m.), and $5 \%$ of the lighting remained on even when the building was vacant. Values for equipment usage ranged from 40 to $90 \%$. The heating and cooling systems operated from 7 a.m. to 10 p.m. during weekdays, and the heating and cooling setpoints were $21^{\circ} \mathrm{C}$ and $24{ }^{\circ} \mathrm{C}$, respectively. In Scenario 2, the setpoint temperatures remained the same as the setpoint temperatures of Scenario 1. It was assumed in Scenario 2, however, that lighting and equipment were not used during non-working hours from 11 p.m. to 6 a.m. Thus internal heat gains were zero from 11 p.m. to 6 a.m. in Scenario 2.

In Scenario 3, setpoint temperatures were not fixed, but were instead determined in accordance with changes in comfort temperatures perceived by occupants. Previous studies $[25,26]$ show that occupant behavior is a critical factor in determining comfort temperatures, and thus occupant behavior has significant energy implications. In Scenario 3, the setpoint temperatures for the VRF system during the cooling season from May 1 to October 31 were determined by the adaptive comfort model of air-conditioned buildings located in South Korea [19]. Scenario 4 addressed practices of occupant use of nighttime free cooling for the ERV. Occupant factor related to nighttime ventilation is an active area of research because it has high potential for reducing cooling energy demands [27]. In this study, 
nighttime free cooling was activated when the indoor temperature was $3 \mathrm{~K}$ higher than the outdoor temperature from 11 p.m. to 6 a.m. Finally, adaptive comfort control and nighttime free cooling were both used in Scenario 5.

\subsection{Simulation Modeling}

Energy simulation software, EnergyPlus [28], was utilized to calculate heating and cooling loads as well as the total energy consumption of heating, ventilating, and air-conditioning (HVAC) systems and plant equipment based on heat balance solutions of the building thermal zones, the HVAC systems, and the plant equipment. EnergyPlus has been extensively validated with analytical and comparative tests, and numerous validation studies show the accuracy and reliability of EnergyPlus.

Modeling of VRF systems in EnergyPlus requires 20 performance curves, because the cooling and heating performances of VRF systems depend on changes in indoor and outdoor conditions, together with their resulting loads. Twenty performance curves were calculated based on a method proposed by Raustad [29].

Key modeling processes for the building in our case study include the control of indoor heating and cooling setpoint temperatures for the VRF system and the activation of the free cooling mode of the ERV. Modeling was completed with EnergyPlus Runtime Language (Erl), which enables simulation modelers to define energy modeling system controls by overriding selected aspects of the EnergyPlus model [30]. The Erl programming code developed in this study decides a daily comfort temperature using the adaptive comfort model at the last simulation time step of each day, and manages the thermostatic control of each zone accordingly. For the implementation of nighttime free cooling, the Erl programming code calculates indoor and outdoor temperatures for each zone at each simulation time step and determines the operation mode of the ERV.

\section{Results}

We first analyzed future hourly weather data created according to the HadCM3 A2 model. As expected, there were clear upward trends in future outdoor temperatures. During the years 1961-1990 (standing for a reference timeframe based on "present day" weather data), the mean outdoor temperature in Seoul from May to October was $20.4^{\circ} \mathrm{C}$ (standard deviation (SD) $=3.7^{\circ} \mathrm{C}$ ). The mean temperature in Seoul increased to $25.1^{\circ} \mathrm{C}\left(\mathrm{SD}=3.6^{\circ} \mathrm{C}\right)$ by the $2080 \mathrm{~s}$ (the future timeframe of the simulation model). A similar trend was found in Tokyo. The mean outdoor temperature in Tokyo during a cooling season from May to October increased from $23.0^{\circ} \mathrm{C}\left(\mathrm{SD}=3.3^{\circ} \mathrm{C}\right)$ in the reference timeframe to $27.8^{\circ} \mathrm{C}\left(\mathrm{SD}=3.2^{\circ} \mathrm{C}\right)$ in the 2080s. There was a relatively weak increasing trend of outdoor temperatures in Hong Kong. The temperature increase from the reference timeframe to the 2080s in Hong Kong was $2.7^{\circ} \mathrm{C}$.

We subsequently investigated how cooling degree-hours are affected by a rise in outdoor temperatures due to future climate change. We calculated cooling degree-hours for a base of $23.3^{\circ} \mathrm{C}$ (CDH23.3) in Seoul, Tokyo, and Hong Kong. The annual CDH23.3 for Seoul, Tokyo, and Hong Kong in a reference timeframe were $37,421,57,467$, and 125,644 , respectively, which means that the projected cooling demands in Hong Kong are the greatest. There was a drastic increase in CDH23.3 in Seoul. The CDH23.3 in Seoul increased to 49,906 in the 2020s, to 62,721 in the 2050s, and to 81,730 in 2080s, which is an increase of $118 \%$. The increase in CDH23.3 from the reference timeframe to the 2080s was $95 \%$ and $37 \%$ in Tokyo and Hong Kong, respectively.

The increase in $\mathrm{CDH} 23.3$ was more evident in months with relatively low outdoor temperatures than in hot months. In Tokyo, the CDH23.3 in May was 2471 in the reference timeframe and 11,122 in the 2080s, which is an increase of $350 \%$. In contrast, the CDH23.3 in Tokyo from August of the reference timeframe to the 2080s increased by $29 \%$. For Hong Kong, which showed a mild trend in increasing outdoor temperatures, the April CDH23.3 increased by $132 \%$ in the 2080 s from the reference timeframe. In particular, the December CDH23.3 in Hong Kong increased to 5608 in the 2080s. 
Our study confirms that future climate change has a negative impact on cooling energy consumption in buildings (Figures 1 and 2). The rise in annual cooling energy consumption from the present day to the 2080s ranged from 13,112 kWh in Hong Kong to 19,930 kWh in Tokyo. The biggest increase in monthly cooling energy consumption in Seoul and Tokyo occurred in August. The cooling energy consumption in August rose by $3989 \mathrm{kWh}$ in Tokyo and by $4159 \mathrm{kWh}$ in Seoul, while the greatest monthly cooling energy consumption in Hong Kong happened in September. The cooling energy consumption of September in Hong Kong was 11,268 $\mathrm{kWh}$ in the reference timeframe, rising to $13,575 \mathrm{kWh}$ in the 2080s.

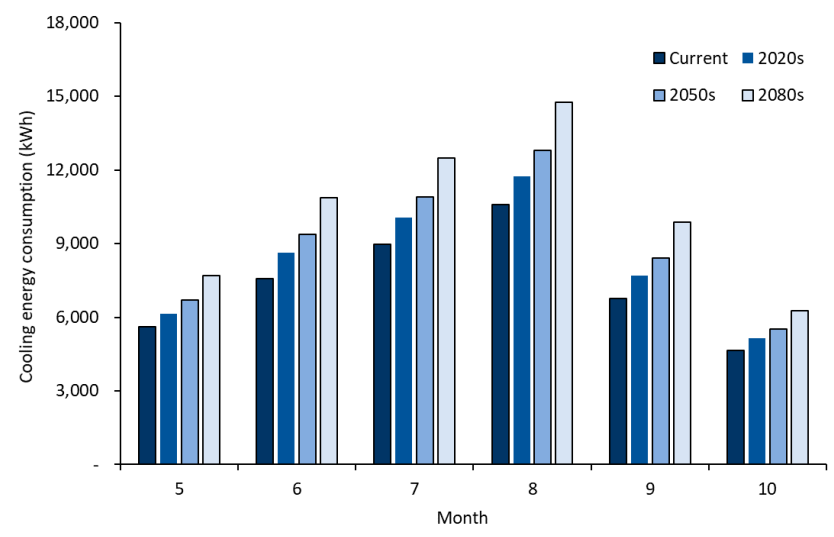

(a)

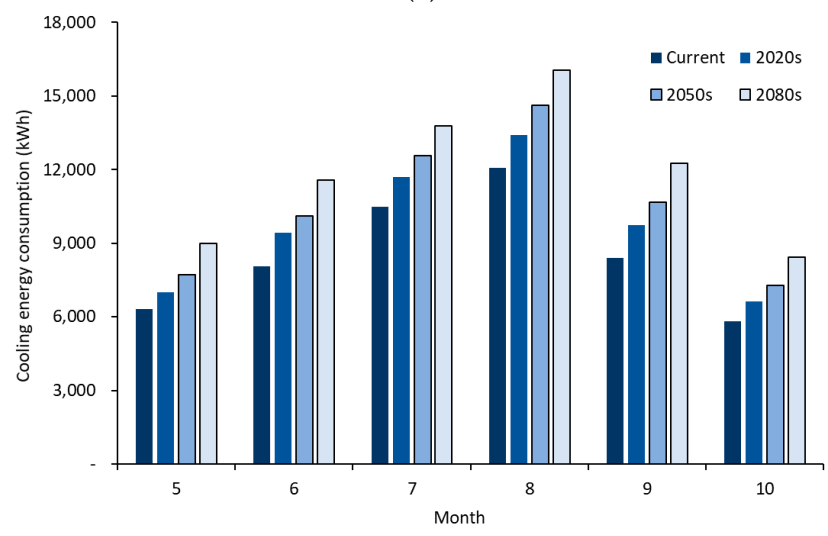

(b)

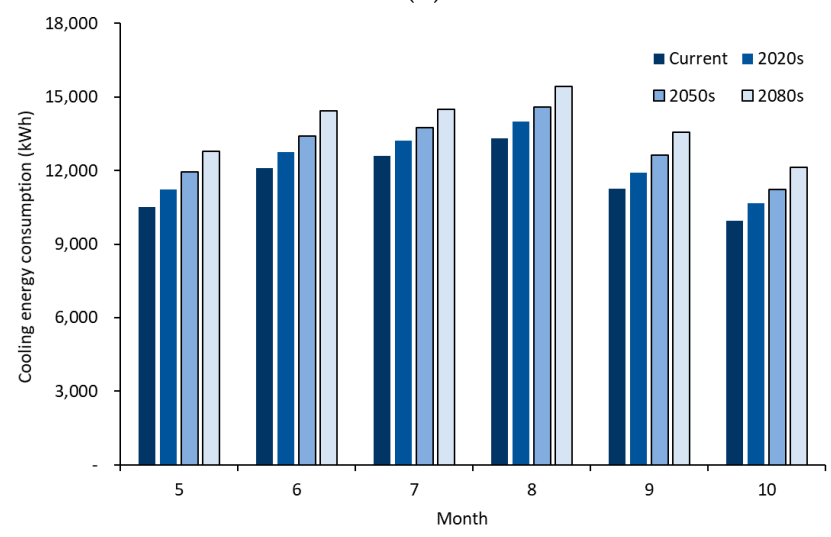

(c)

Figure 1. Cooling energy consumption as a function of future climate change: (a) Seoul; (b) Tokyo; and (c) Hong Kong. 


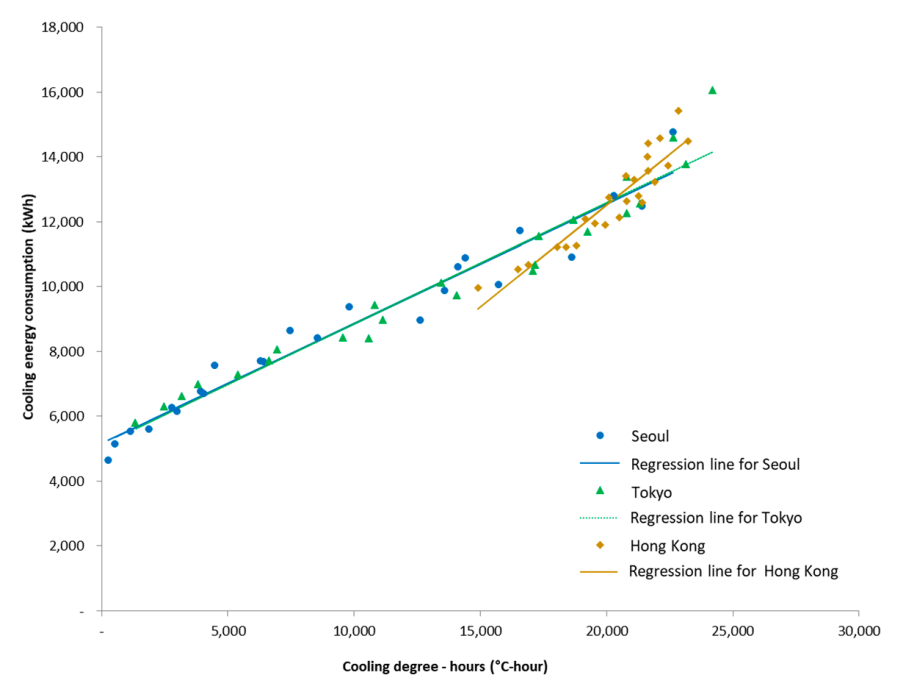

Figure 2. Relationships between a cooling degree-hours base of $23.3^{\circ} \mathrm{C}(\mathrm{CDH} 23.3)$ and cooling energy consumption (kWh).

The simulation results indicate that the use of lighting and equipment is a key factor in determining cooling energy demands. Figure 3 illustrates the effects of occupancy-based use of lighting and equipment on cooling energy consumption from 11 p.m. to 6 a.m. (during building vacancy). In Scenario 2, it was assumed that lighting and equipment were turned off from 11 p.m. to 6 a.m. during building vacancy, while the ratio of equipment turned on was $40 \%$ in the base case scenario. The results show that this occupancy-based use of lighting and equipment during non-occupied periods in buildings reduced cooling energy consumption in Seoul, Tokyo, and Hong Kong. The cooling energy consumption of the building in Seoul in the reference timeframe was reduced by $10.3 \%$, while the cooling energy consumption in the building in Hong Kong was reduced by $8.1 \%$. The degree of increase in cooling energy consumption in buildings in each of the three cities became weak as climate change proceeded. The cooling energy consumption in Seoul was $10.3 \%$ in the reference timeframe and $8.7 \%$ in the $2080 \mathrm{~s}$.

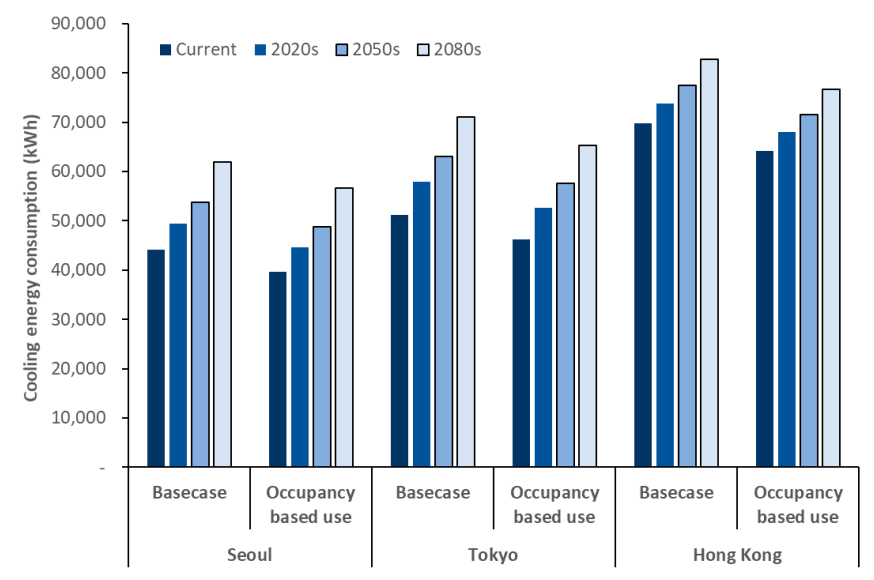

Figure 3. Effects of the efficient use of lighting and equipment during non-working hours on cooling energy consumption.

Figure 4 illustrates the energy saving potential of an adaptive comfort control that regulates cooling setpoint temperatures as a function of changes in outdoor temperatures. Energy savings due to the adaptive comfort control were highest in Hong Kong. Respective reductions in the cooling energy consumption of buildings in the reference timeframe were $17.4 \%$ in Hong Kong, $13.3 \%$ in Tokyo, and 
$11.3 \%$ in Seoul. The potential energy savings of the adaptive comfort control increased as projected climate changes progressed. The rate of cooling energy savings in Seoul was $11.3 \%$ in the reference timeframe, increasing to $15.7 \%$ in the 2080 s. This trend of increased cooling energy savings was also observed in Tokyo. The degree of cooling energy reduction in Tokyo fluctuated from $7.4 \%$ in the reference timeframe to $17.8 \%$ in the $2080 \mathrm{~s}$.

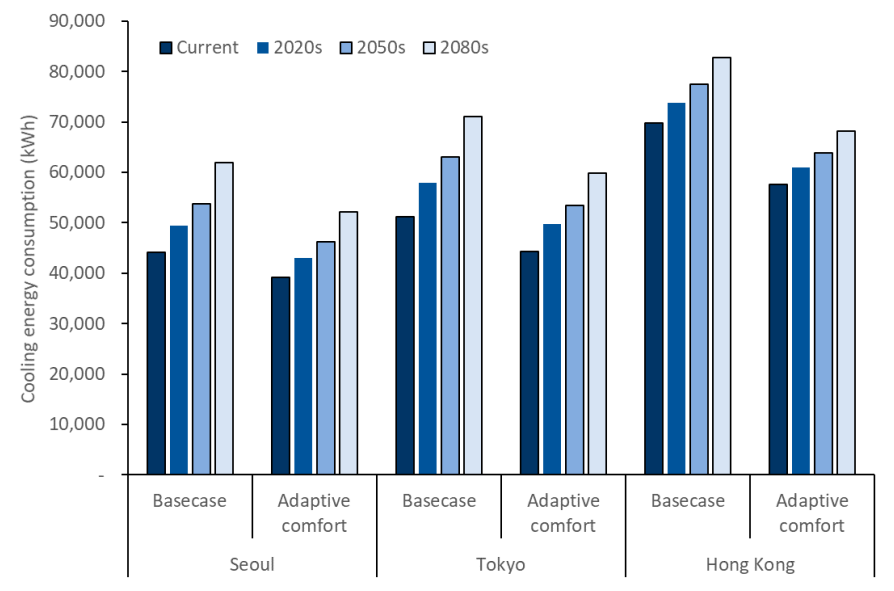

Figure 4. Effects of adaptive comfort control on cooling energy consumption.

Cooling energy savings due to the application of nighttime ventilation were highly dependent on outdoor air temperature conditions (Figure 5). Among the three cities, the reduction in cooling energy consumption was smallest in Hong Kong, where outdoor temperatures were highest. In the reference timeframe in Hong Kong, the cooling energy consumption due to nighttime ventilation was reduced by $412 \mathrm{kWh}(0.6 \%)$, and the mean outdoor temperature from May to October was $27.1^{\circ} \mathrm{C}$ $\left(\mathrm{SD}=3.4^{\circ} \mathrm{C}\right)$. The energy saving potential of nighttime ventilation was largest in Seoul, where outdoor temperatures were lower than outdoor temperatures in Tokyo and Hong Kong during the simulation timeframes. The reduction of the cooling energy consumption in Seoul was $6.4 \%$ in the reference timeframe. This reduction rate of cooling energy consumption in Seoul was dependent on a rise in outdoor temperatures due to climate change. The reduction in cooling energy consumption in Seoul was $6.4 \%$ in the reference timeframe, during which the mean outdoor temperature from May to October was $20.4{ }^{\circ} \mathrm{C}\left(\mathrm{SD}=3.7^{\circ} \mathrm{C}\right)$. However, this reduction decreased to $2.8 \%$ in the 2080 s when the mean outdoor temperature increased to $25.1^{\circ} \mathrm{C}\left(\mathrm{SD}=3.6^{\circ} \mathrm{C}\right)$.

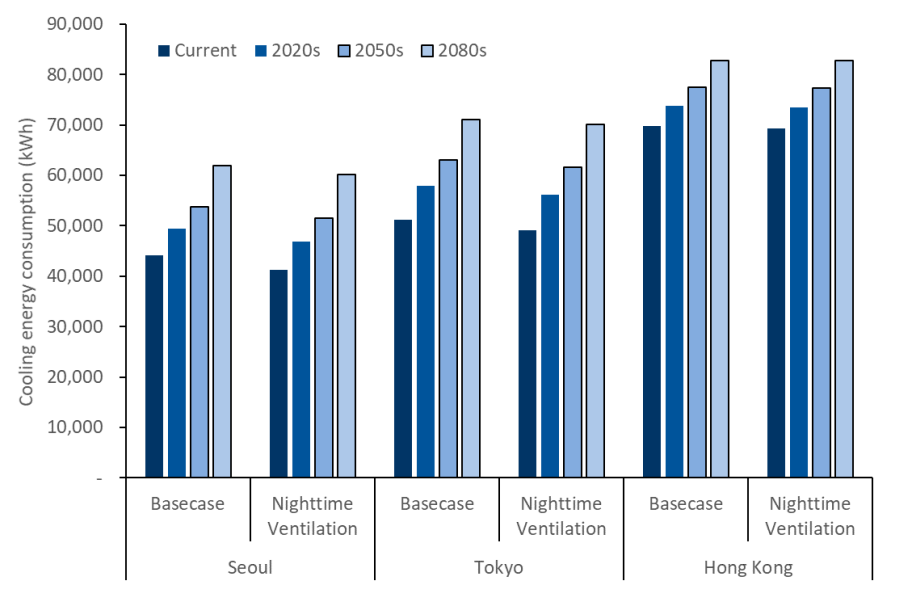

Figure 5. Implications of climate change on cooling energy savings by the application of nighttime ventilation. 
After we analyzed the effects of individual occupant behavioral factors, we examined the combined effects of occupant behavioral factors on cooling energy consumption in Seoul, Tokyo, and Hong Kong (Figure 6). In terms of behavioral changes, the modification of thermostat setpoints based on the adaptive comfort model was the most effective method to reduce cooling energy consumption, followed by turning off lighting and equipment during periods of vacancy in buildings. Although the extent of energy savings due to nighttime ventilation was limited, particularly in Hong Kong, the combined use of adaptive comfort controls and nighttime ventilation was effective in reducing energy consumption. In Hong Kong, cooling energy savings increased from $0.6 \%$ with the application of nighttime ventilation only to $20.2 \%$ with the combined use of nighttime ventilation and adaptive comfort control. The combination of adaptive comfort control and occupancy-based use of lighting and equipment during periods of vacancy in buildings was also an effective solution. Energy savings due to the combined use of adaptive comfort control and occupancy-based use of lighting and equipment in the reference timeframe was $20.9 \%$ in Seoul, $22.4 \%$ in Tokyo, and $24.9 \%$ in Hong Kong. The energy saving potential increased with future climate change. For example, the ratio of energy savings in Seoul increased from $20.9 \%$ in the reference timeframe to $23.7 \%$ in the 2080s.

The energy saving potential was greatest when the three behavioral factors considered in this study were comprehensively applied. In Seoul, the combined application of adaptive comfort controls, nighttime ventilation, and occupancy-based lighting and equipment use resulted in the reduction of cooling energy consumption by $27.9 \%$ in the reference timeframe. This trend in reduced cooling energy consumption due to the combined application of behavioral changes on the part of building occupants remained effective under scenarios of future climate change. The projected cooling energy consumption in Seoul was $44,819 \mathrm{kWh}$ in the $2080 \mathrm{~s}$, representing a $27.6 \%$ reduction in cooling energy consumption. This indicates that the combined use of certain occupant behavioral factors is an effective adaptive solution to the foreseeable problems of climate change. In Seoul, the measure of cooling energy consumption in the 2080s $(44,819 \mathrm{kWh})$ from joint application of the three behavioral factors was similar to the cooling energy consumption of the base case in the reference timeframe $(44,136 \mathrm{kWh})$.

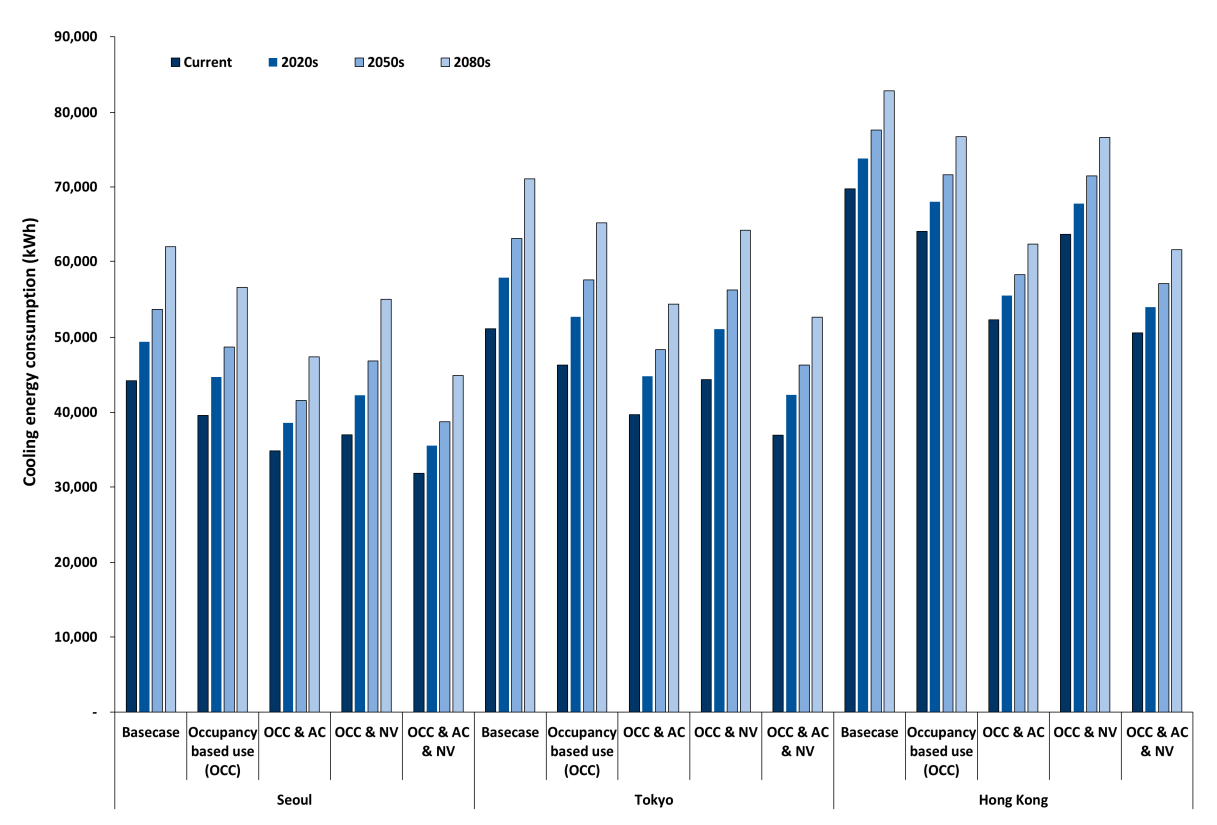

Figure 6. Effects of occupant behavioral factors on cooling energy consumption.

\section{Discussion and Conclusions}

Our study projects future hourly weather data using the morphing method for Seoul, Tokyo, and Hong Kong based on the HadCM3 A2 model. Using the future weather data, this study finds that 
cooling degree-hours based on $23.3^{\circ} \mathrm{C}$ (CHD 23.3) from the reference timeframe to the 2020s drastically increased from 37,421 to 81,730 in Seoul; from 57,467 to 112,248 in Tokyo; and from 125,644 to 172,344 in Hong Kong. The results also show that CHD23.3 is closely related to cooling energy consumption. For example, an $R^{2}$ value for the relationship between $\mathrm{CDH} 23.3$ and the cooling energy consumption in Seoul was $0.96\left(\mathrm{~F}_{(1,22)}=475, p<0.01\right)$. Previous studies [31,32] on the impacts of climate change on building energy consumption have mainly focused on the use of cooling degree days. The application of cooling degree-hours adopted herein may be further used for extreme weather situations in different parts of the world.

One of the outcomes of this study is the quantification of the effects of adaptive comfort control on current and future cooling energy consumption in the context of climate change. This study reveals that a dynamic thermostat control-based adaptive comfort model has great energy saving potential in each of the three cities, and that reductions in cooling energy consumption due to the adaptive comfort control increases as climate change proceeds. The reduction in cooling energy consumption in Seoul was $11.3 \%$ in the reference timeframe, rising to $15.7 \%$ in the 2080 s. Existing studies $[33,34]$ show that adaptive comfort models have significant energy saving effects. A study by McCartney and Nicol (2002) shows energy savings of 30\% due to the use of an adaptive comfort control in Europe. Likewise, the work of Mui and Chan [34] finds a reduction in cooling energy consumption of $7 \%$ in Hong Kong due to adaptive comfort control strategies. This study proves that adaptive comfort control is an effective energy saving strategy under future climate change. The application of the adaptive comfort model in buildings is an important strategy to mitigate the effects of greenhouse gases from buildings and to adapt buildings for the foreseeable conditions of climate change [35].

Our study shows that the application of nighttime ventilation is not always effective in reducing cooling energy consumption, but that its cooling potential is improved when used in combination with other control methods related to occupant behavioral factors. In particular, energy savings due to nighttime ventilation in Hong Kong was minimal. Only $0.6 \%$ of the overall cooling energy consumption was reduced in the reference timeframe in Hong Kong. This finding is in line with the results of previous studies [36,37]. Existing studies have revealed that the effectiveness of nighttime ventilation is highly dependent on outside weather conditions, and that the cooling potential of nighttime ventilation lessens with an increase in outdoor temperatures. This study finds that the effectiveness of nighttime ventilation may be improved by its integration with other control methods related to occupant behavioral factors. The work of Solgi et al. [38], for example, shows that integrating phase-change materials and nighttime ventilation potentially reduces the cooling load of buildings.

This study extends our current understanding of the role of occupant factors in the overall energy consumption of buildings by revealing the cooling energy saving potential of adaptive comfort control under climate change projections. This study shows that the rational regulation of buildings in terms of occupant behavioral factors demonstrates high potential for adapting buildings to the effects of climate change and mitigating the effects of greenhouse gas emissions on the environment. According to simulations, cooling energy consumption drastically increases as future climate change proceeds. For example, the increase in cooling energy consumption from the reference timeframe to the 2080s ranged from 19\% in Hong Kong to 40\% in Seoul. This study shows that we can compensate for this increase in cooling energy consumption under future climate change with efficient controls related to occupant behavioral factors, such as turning off lighting and equipment during periods of vacancy in buildings, the use of adaptive comfort models for thermostat control, and the application of nighttime ventilation. The outcomes of this study are useful to provide cost-effective solutions to adapt buildings for the conditions of future climate change through the simple modification of occupant factors. This is supported by previous studies $[4,39]$ that illustrate the high potential of occupant behavior factors in reducing energy consumption in cost-effective ways under climate change.

The outcomes of this study imply that the principles of passive buildings would be particularly useful for the design and refurbishment of a building. In particular, the education of occupants and facility managers is of importance to minimize the negative impacts of climate change. 
It should be also mentioned that the deployment of renewable energies in buildings provides important benefits for dealing with climate change challenges. A photovoltaic (PV) system has been successfully integrated into the buildings since the early 1990s [40], which can mitigate climate change by reducing greenhouse gas (GHG) emissions. For example, the use of building integrated photovoltaic envelope is useful to displace the heating and cooling energy consumption within a building [41]. In particular, a recent study [42] shows that the PV system is a reliable renewable option in the future as the electricity generation of the PV system increases under climate change scenarios by the Intergovernmental Panel on Climate Change. Micro wind turbines have been also recognized as efficient options for buildings. Micro wind turbines can be mounted on high-rise buildings so that the wind turbines are exposed to higher wind velocities compared to the ground [43]. Future studies should investigate the potential roles of the renewable systems in buildings under future climate conditions.

Acknowledgments: This work was supported by the National Research Foundation of Korea (NRF) grant funded by the Basic Science Research Program through the National Research Foundation of Korea (NRF) funded by the Ministry of Science, ICT and Future Planning (NRF-2017R1D1A1A09000639).

Author Contributions: G.Y.Y. designed the research methods, analyzed the data, and wrote the paper. J.H.L. performed simulations and developed the research methods.

Conflicts of Interest: The authors declare no conflict of interest.

\section{References}

1. Intergovernmental Panel on Climate Change. Climate Change 2014: Mitigation of Climate Change; Cambridge University Press: New York, NY, USA, 2014.

2. Hales, S.; Kovats, S.; Lloyd, S.; Campbell-Lendrum, D. Quantitative Risk Assessment of the Effects of Climate Change on Selected Causes of Death, 2030s and 2050s; World Health Organization: Geneva, Switzerland, 2014.

3. IEA (International Energy Agency). World Energy Outlook 2014; International Energy Agency: Paris, France, 2014.

4. UNEP (United Nations Environment Programme). Building and Climate Change: Summary for Decision-Makers; United Nations Environment Programme: Paris, France, 2009.

5. Yun, G.Y.; Shin, H.Y.; Kim, J.T. Monitoring and evaluation of a light-pipe system used in Korea. Indoor Built Environ. 2010, 19, 129-136.

6. Fang, Z.; Li, N.; Li, B.; Luo, G.; Huang, Y. The effect of building envelope insulation on cooling energy consumption in summer. Energy Build. 2014, 77, 197-205. [CrossRef]

7. Yun, G.Y.; Choi, J.; Kim, J.T. Energy performance of direct expansion air handling unit in office buildings. Energy Build. 2014, 77, 425-431. [CrossRef]

8. Girard, A.; Gago, E.J.; Muneer, T.; Caceres, G. Higher ground source heat pump COP in a residential building through the use of solar thermal collectors. Renew. Energy 2015, 80, 26-39. [CrossRef]

9. Missaoui, R.; Joumaa, H.; Ploix, S.; Bacha, S. Managing energy smart homes according to energy prices: Analysis of a building energy management system. Energy Build. 2014, 71, 155-167. [CrossRef]

10. Norford, L.K.; Socolow, R.H.; Hsieh, E.S.; Spadaro, G.V. Two-to-one discrepancy between measured and predicted performance of a 'low-energy' office building: Insights from a reconciliation based on the DOE-2 model. Energy Build. 1994, 21, 121-131. [CrossRef]

11. De Wilde, $P$. The gap between predicted and measured energy performance of buildings: A framework for investigation. Autom. Constr. 2014, 41, 40-49. [CrossRef]

12. Hoes, P.; Hensen, J.; Loomans, M.; De Vries, B.; Bourgeois, D. User behavior in whole building simulation. Energy Build. 2009, 41, 295-302. [CrossRef]

13. Dietz, T.; Gardner, G.T.; Gilligan, J.; Stern, P.C.; Vandenbergh, M.P. Household actions can provide a behavioral wedge to rapidly reduce US carbon emissions. Proc. Natl. Acad. Sci. USA 2009, 106, 18452-18456. [CrossRef] [PubMed]

14. Yun, G.Y.; Kim, H.; Kim, J.T. Effects of occupancy and lighting use patterns on lighting energy consumption. Energy Build. 2012, 46, 152-158. [CrossRef]

15. Feng, X.; Yan, D.; Hong, T. Simulation of occupancy in buildings. Energy Build. 2015, 87, 348-359. [CrossRef] 
16. Yun, G.Y.; Steemers, K. Time-dependent occupant behaviour models of window control in summer. Build. Environ. 2008, 43, 1471-1482. [CrossRef]

17. Andersen, R.; Fabi, V.; Toftum, J.; Corgnati, S.P.; Olesen, B.W. Window opening behavior modelled from measurements in Danish dwellings. Build. Environ. 2013, 69, 101-113. [CrossRef]

18. Schweiker, M.; Shukuya, M. Comparison of theoretical and statistical models of air-conditioning-unit usage behavior in a residential setting under Japanese climatic conditions. Build. Environ. 2009, 44, 2137-2149. [CrossRef]

19. Yun, G.Y.; Kong, H.J.; Kim, J.T. The Effect of Seasons and Prevailing Environments on Adaptive Comfort Temperatures in Open Plan Offices. Indoor Built Environ. 2012, 21, 41-47. [CrossRef]

20. ASHRAE (American Society of Heating, Refrigerating, and Air-conditioning Engineers). ANSI/ASHRAE Standard 90.1-2013 Energy Standard for Buildings except Low-Rise Residential Buildings. 2013. Available online: https:/ / osr.ashrae.org/Public\%20Review\%20Draft\%20Standards\%20Lib/90.1cz_1stPPRDraft.pdf (accessed on 6 November 2017).

21. Sustainable Energy Research Group. Climate Change World Weather File Generator for World-Wide Weather Data-CCWorldWeatherGen; University of Southampton: Southampton, UK, 2009.

22. Belcher, S.; Hacker, J.; Powell, D. Constructing design weather data for future climates. Build. Serv. Eng. Res. Technol. 2005, 26, 49-61. [CrossRef]

23. Jentsch, M.F.; James, P.A.; Bourikas, L.; Bahaj, A.S. Transforming existing weather data for worldwide locations to enable energy and building performance simulation under future climates. Renew. Energy 2013, 55, 514-524. [CrossRef]

24. Deru, M.; Field, K.; Studer, D.; Benne, K.; Griffith, B.; Torcellini, P. Commercial Reference Building Models of the National Building Stock; National Renewable Energy Laboratory: Golden, CO, USA, 2011.

25. Haldi, F.; Robinson, D. The impact of occupants' behavior on building energy demand. J. Build. Perform. Simul. 2011, 4, 323-338. [CrossRef]

26. Humphreys, M.A.; Rijal, H.B.; Nicol, J.F. Updating the adaptive relation between climate and comfort indoors; new insights and an extended database. Build. Environ. 2013, 63, 40-55. [CrossRef]

27. Santamouris, M.; Kolokotsa, D. Passive cooling dissipation techniques for buildings and other structures: The state of the art. Energy Build. 2013, 57, 74-94. [CrossRef]

28. US DOE (U.S. Department of Energy). Input Output Reference-The Encyclopedic Reference to EnergyPlus Input and Output; US Department of Energy: Washington, DC, USA, 2013.

29. Raustad, R. Computer Modeling VRF Heat Pumps in Commercial Buildings using EnergyPlus. ASHRAE Trans. 2013, 119, 10.

30. US DOE (U.S. Department of Energy). Application Guide for EMS: Energy Management System User Guide (a.k.a. The Book of Erl); US Department of Energy: Washington, DC, USA, 2013.

31. Cox, R.A.; Drews, M.; Rode, C.; Nielsen, S.B. Simple future weather files for estimating heating and cooling demand. Build. Environ. 2015, 83, 104-114. [CrossRef]

32. De Rosa, M.; Bianco, V.; Scarpa, F.; Tagliafico, L.A. Historical trends and current state of heating and cooling degree days in Italy. Energy Convers. Manag. 2015, 90, 323-335. [CrossRef]

33. McCartney, K.J.; Fergus Nicol, J. Developing an adaptive control algorithm for Europe. Energy Build. 2002, 34, 623-635. [CrossRef]

34. Mui, K.W.H.; Chan, W.T.D. Adaptive comfort temperature model of air-conditioned building in Hong Kong. Build. Environ. 2003, 38, 837-852. [CrossRef]

35. Kwok, A.G.; Rajkovich, N.B. Addressing climate change in comfort standards. Build. Environ. 2010, 45, 18-22. [CrossRef]

36. Yun, G.Y.; Steemers, K. Night-time naturally ventilated offices: Statistical simulations of window-use patterns from field monitoring. Sol. Energy 2010, 84, 1216-1231. [CrossRef]

37. Ramponi, R.; Gaetani, I.; Angelotti, A. Influence of the urban environment on the effectiveness of natural night-ventilation of an office building. Energy Build. 2014, 78, 25-34. [CrossRef]

38. Solgi, E.; Fayaz, R.; Kari, B.M. Cooling load reduction in office buildings of hot-arid climate, combining phase change materials and night purge ventilation. Renew. Energy 2016, 85, 725-731. [CrossRef]

39. Intergovernmental Panel on Climate Change. Climate Change 2014: Impacts, Adaptation, and Vulnerability; Cambridge University Press: New York, NY, USA, 2014. 
40. Yang, T.; Athienitis, A.K. A review of research and developments of building-integrated photovoltaic/thermal (BIPV/T) systems. Renew. Sustain. Energy Rev. 2016, 66, 886-912. [CrossRef]

41. Yun, G.Y.; McEvoy, M.; Steemers, K. Design and overall energy performance of a ventilated photovoltaic façade. Sol. Energy 2007, 81, 383-394. [CrossRef]

42. Shen, P.; Lior, N. Vulnerability to climate change impacts of present renewable energy systems designed for achieving net-zero energy buildings. Energy 2016, 114, 1288-1305. [CrossRef]

43. Kolokotsa, D. Smart cooling systems for the urban environment. Using renewable technologies to face the urban climate change. Sol. Energy 2017, 154, 101-111. [CrossRef]

(C) 2017 by the authors. Licensee MDPI, Basel, Switzerland. This article is an open access article distributed under the terms and conditions of the Creative Commons Attribution (CC BY) license (http:/ / creativecommons.org/licenses/by/4.0/). 